\title{
The enforcement of the global sulfur cap in maritime transport
}

\begin{abstract}
Purpose - The International Maritime Organization has decided that as of 1.1.2020, SOx content in a ship's emissions should be no more than 0.5 per cent. The purpose of this paper is to address the various challenges expected to arise from the enforcement of the global cap sulfur regulation.
\end{abstract}

Design/methodology/approach - The authors outline various enforcement options and present a model that calculates the profits from noncompliance in the high seas, so as to help determine the level of fines that could be imposed in case of violation.

Findings - The main finding is that a harmonized system of fines, which are more than potential savings from cheating, would be a strong deterrent for compliance.

Originality/value - To the authors' knowledge, no paper in the maritime literature on sulfur regulations has focused on enforcement as of yet.

Keyword Global sulfur cap

Paper type Research paper

\section{Introduction}

The International Maritime Organization (IMO) has been very active in formulating regulations in an effort to minimize pollution released from ships either in the marine environment or in the atmosphere. A regulation focusing on the sulfur emissions has been introduced by the IMO and will be put into force on January 1, 2020. The global sulfur cap, as the regulation is called, will limit the sulfur content of the fuel used for vessels' propulsion to 0.5 per cent. The current regulation allows a percentage of 3.5 per cent sulfur in fuel for all vessels sailing in the high seas, outside regulated areas and the residual fuels available in the market usually contain approximately 2.7 per cent sulfur. Therefore, compliance with the regulation in the high seas has not been an issue for the ship owners. This regulation is part of ANNEX VI of the MARPOL convention: Regulations for the Prevention of Air Pollution from Ships (IMO, 1978). As expected, the upcoming global sulfur cap has been for a very long time a much-debated topic in the shipping world that was waiting for IMO's critical decision regarding the implementation date of the cap. The shipping and refining industry have shown a phenomenal interest in the date the cap would be set in force, as their actions are highly dependent on the timing of the regulations.

(C) Pacific Star Group Education Foundation. Licensed re-use rights only.

The authors would like to thank Jon Knudsen, CEO of Explicit ApS for his assistance and information about the airborne monitoring with UAVs in Denmark and Dorte Kubel at the Danish EPA for the valuable information about the inspections in Danish waters conducted by the Danish EPA. They are also indebted to Elizabeth Lindstad of SINTEF Ocean and to Poul Woodall of DFDS for their comments on previous versions of the manuscript and to Thalis Zis of DTU for his assistance on the numerical part of the paper.

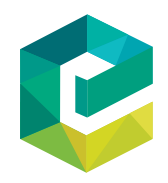

Maritime Business Review Vol. 4 No. 2, 2019 pp. $199-216$ Emerald Publishing Limited DOI 10.1108/MABR-12-2018-0050 
MABR

4,2

200
The IMO was set to decide about the implementation date based on the results of the fuel availability study that was conducted by CE Delft (2016). The aim of the study was to assess the ability of the refining industry to produce enough low sulfur fuel for the shipping industry that could cover the demand once the regulations are set in force. In October 2016, the 70th session of IMO's Marine Environment Protection Committee (MEPC 70) met to examine the results of the fuel availability study and decided that the implementation date should be set to January 1, 2020 rather than wait until 2025. According to the results of CE Delft study, the refining industry has enough time to adapt the production to the new requirements of the global sulfur cap. Alternative methods of compliance were taken into account for the calculations of the expected demand of compliant fuel in 2020. The study examined three scenarios of the fuel demand, a base case, a high-demand case for marine fuels with sulfur content less than 0.5 per cent and a low-demand case in which more ships will be equipped with alternative compliance options and less are going to use low sulfur fuel.

It is interesting to note here that an alternative study conducted by EnSys Energy and Navigistics Consulting was also submitted to the IMO on behalf of various stakeholders, among them BIMCO and IPIECA (Ensys Energy and Navigistics Consulting, 2016). Even though this study estimated a higher number of ships with scrubbers than the original CE Delft study, it claimed that most operators would not have equipped their ships with such systems by 2020 and the only way of compliance would be low sulfur fuel. If that is the case, the refining industry would not have enough time to prepare for the high demand of such fuels that would occur overnight, thus implying shifting the implementation date to $1 / 1$ / 2025. However, the IMO found these concerns unsubstantiated and after considerable discussion decided to move forward with the 1/1/2020 date as opposed to 1/1/2025. Still, between 2016 and 2018 there was considerable discussion on the subject, as some industry circles voiced concerns on safety issues as regards low sulfur fuels. The latest and perhaps "landmark" decision on this subject was reached by the IMO at MEPC 73 (October 2018), to ban non-compliant fuels from ships that do not use scrubbers, as of March 1, 2020. This is the so-called "carriage ban" policy, which will be discussed later in the paper.

The literature on sulfur regulations and specifically on their possible impacts is worthy of note. For instance, a special issue of Transportation Research Part D was dedicated to discussing Emissions Control Areas (ECAs) and their impact on maritime transport (Cullinane and Bergqvist, 2014). Among other papers in that issue, Panagakos et al. (2014) discussed the possible designation of the Mediterranean as a sulfur emissions control area (SECA), and Jiang et al. (2014) analyzed the costs and benefits of the scrubber solution vis-'avis low sulfur fuels. Fagerholt et al. (2015), and Fagerholt and Psaraftis (2015), developed models that optimize routes and speeds for ships that sail in and out of ECAs and switch fuel whenever they cross an ECA border. Zis and Psaraftis $(2017,2018)$ investigated the possible impacts of sulfur regulations on the Ro-Ro sector in Northern Europe, by developing enhanced modal split models that attempt to calculate the possible shifts to other modes. Several measures to mitigate or reverse the negative repercussions of such legislation have also been proposed. Lindstad and Eskeland (2016) showed that the scrubber option gives lowest cost for large vessels even with low fuel prices. A similar and more recent result was shown by Lindstad et al. (2017) in the context of sulfur abatement options for the global sulfur cap. They concluded that scrubbers are a more attractive option for larger vessels whereas low sulfur fuels seem more positive for smaller vessels. Svindland (2018) addressed the environmental effects of ECA regulations on container feeder vessels in Northern Europe. 
We note however that none of the above papers, and to our knowledge no papers in the scientific literature on sulfur regulations, have explicitly addressed the enforcement issues associated with the 2020 global sulfur cap. Our paper attempts to contribute to this subject, by examining, inter alia, penalty policies that need to be followed so that potential violations are discouraged. When the global sulfur cap was introduced, penalties were not defined for the non-compliant ships but were left to be decided by the responsible authorities. However, these penalties need to be universal and the fines to the disobeying operators should also work as motivating factors to encourage compliance in the high seas. One of the aims of the paper is to identify and assess the existing and potential methods to monitor and control sulfur emissions in a way that will ensure a level playing field. In addition, the penalty policies that need to be decided before the implementation date are analyzed and a method to calculate fines for ships violating the regulations in the high seas is developed. Port state and flag state control authorities need to have a simple and quick tool to estimate a sufficient fine for the non-compliant ships. The calculation is using data about the ship's route and average fuel consumption per trip. The distance covered, transit time and speed along with the engine specifications can give us an approximate calculation of the fuel burnt and allow the definition of a penalty that will be a considerable loss for the non-compliant ship operators.

The rest of this paper is organized as follows: Section 2 provides a short explanation of the current and future sulfur regulations. Section 3 examines the compliance options for the ship operators in 2020. Section 4 provides a presentation of the available and potential enforcement schemes. Section 5: presents a model to calculate fines for non-compliant ships based on fuel consumption. Section 6 suggests possible penalties to be imposed for the violations and Section 7 presents the conclusions.

\section{Sulfur regulations}

The most widely used fuel in the shipping industry is the residual fuel oil, the most popular of which are RMG and RMK with a viscosity of 380 and $700 \mathrm{cSt}$, respectively, or less. Over the years, all marine engines are able to burn this type of fuel as the low price of HFO (Heavy Fuel Oil) has established it as the main marine fuel. Bunker fuel when burnt releases an important amount of pollutants, the most significant of which are sulfur and nitrogen oxides $\left(\mathrm{SO}_{\mathrm{x}}\right.$ and $\left.\mathrm{NO}_{\mathrm{x}}\right)$, carbon monoxide and dioxide $\left(\mathrm{CO}\right.$ and $\mathrm{CO}_{2}$ respectively), black carbon (BC) and various kinds of particulate matter (PM) (International Transport Forum, 2016), (Molloy, 2016). Carbon and sulfur contained in the bunker fuel oil are oxidized to $\mathrm{CO}_{2}$ and sulfur oxides, mainly sulfur dioxide, $\mathrm{SO}_{2}$. In the engine of the ship, nitrogen $\left(\mathrm{N}_{2}\right)$ is oxidized to nitrogen oxides $\left(\mathrm{NO}_{\mathrm{x}}\right)$, which, along with the sulfur oxides, when they reach the atmosphere, are converted into fine particles, sulfate and nitrate aerosols (Press Kristensen et al., 2011). The most dangerous of sulfur oxides is the sulfur dioxide $\left(\mathrm{SO}_{2}\right)$ which is the main cause for acid rain. Ports and areas with heavy industry have higher concentrations of $\mathrm{SO}_{2}$ and the population is more often suffering from respiratory problems [USA Environmental Protection Agency (EPA), 2016].

The areas designated as ECAs by MARPOL Annex VI are currently the following: the Baltic Sea; the North Sea; the North American area, 200 nautical miles offshore USA and Canada, including Hawaii, St. Lawrence Waterway and the Great Lakes, and the USA Caribbean Sea area. They are often referred to as Sulfur Emission Control areas (SECAs) or Nitrogen Emission Control areas (NECAs) because of the sulfur and nitrogen regulations imposed. According to MARPOL Annex VI, the global limit for the sulfur content since January 1, 2012 (and up to December 31, 2019) is 3.5 per cent. A new global cap will be 
MABR

4,2

202 imposed as from January 1, 2020 that will limit the sulfur emissions to 0.5 per cent. The current limit for the ECA zones is 0.1 per cent and it is in force since January 1, 2015.

Action on sulfur has been taken by other countries as well. For instance, China including Hong Kong has designated some coastal areas as ECAs. The new regulations were announced in 2015 and designated the areas near the Pearl River Delta, Yangtze River Delta and the Bohai Sea as ECAs. The new requirements oblige all ships sailing inside ECAs or certain ports inside these areas to reduce emissions of sulfur oxides to 0.5 per cent.

\section{Compliance options}

There are three main compliance options that will allow the vessels to be compliant in the ECA zones and the high seas. The limits differ so it is necessary to pay attention before deciding which method is more efficient in every case. The categories are:

- compliant fuels (other than liquefied natural gas [LNG]);

- LNG; and

- emission abatement methods, also referred to as scrubbers.

Marine fuels with low sulfur content include marine gas oil (MGO) and marine diesel oil (MDO), as well as hybrid fuels, which are usually a mixture of HFO and distillates. Blended fuels, as they are also called, are a cheaper alternative that was developed recently to comply with the 0.1 per cent limit in the ECA zones. The so-called low sulfur fuel oil (LSFO) is a fuel oil variant with maximum 0.5 per cent sulfur[1]. Similar fuels with a maximum sulfur content of 0.5 per cent will be produced to ensure compliance in the high seas. MGO and $\mathrm{MDO}$ do not require major alterations in the main engine, which leads to low capital investment and makes it the most appealing option.

Compliant fuels appear to be the most popular method of compliance for 2020 because of the reduced initial investment cost. Their availability in every port is still an open issue. Compliant fuels include also alternative fuels, which are not petroleum products. Most commonly used among these are biofuels, dimethyl ether, ethane and methanol. Alternative fuels might require alterations in the main engine before using them but the main limitation is their unavailability in many ports. Unlike the low sulfur fuels, alternative fuels are harder to find and their market share has never been high.

Another solution for fuel compliance is LNG. LNG offers a reduction of sulfur emissions almost 100 per cent, of $\mathrm{CO}_{2}$ emissions $20-25$ per cent, of particulate matter 98-100 per cent and $\mathrm{NO}_{\mathrm{x}}$ removal up to 80-90 per cent (Lloyd's Register, 2012). The number of LNG fueled ships is constantly increasing, with a number of more than 75 operating ships and another 80 expected to be built in the next three years (Ship and Bunker News Team, 2017). LNG provides compliance with all existing regulations without any additional investments, but the original cost of the installation is high with a usually long payback period that may not work in favor of its expansion. The LNG installation may be profitable in some new buildings and usually in vessels with a fixed route that spend a lot of time inside ECA zones. Potential problems with LNG include:

- possible scarcity of bunkering locations;

- price volatility; and

- the so-called "methane slip", which involves the release of methane emissions because of imperfect burning in the vast majority of marine engines (4-stroke and 2stroke dual fuel or Otto cycle -spark plug- engines).

Methane $\left(\mathrm{CH}_{4}\right)$ is a greenhouse gas that is at least 25 times more potent than $\mathrm{CO}_{2}$. 
A popular alternative to low sulfur fuels are the emission abatement systems, commonly known as scrubbers. The scrubber is a device that treats the exhaust gases with a chemical solution through seawater or freshwater aiming in removing part or the total of $\mathrm{SO}_{\mathrm{x}}$ from the gases and reducing PM. The cleaner exhaust is then released to the atmosphere and the neutralized $\mathrm{SO}_{\mathrm{x}}$ and $\mathrm{PM}$ along with the solution used are released as waste in the sea. The most common type of scrubber used in marine installations is the wet scrubber.

In wet scrubbers, the sulfurous gases dissolve in the seawater or fresh water enriched with sodium hydroxide, producing sodium sulfate salt, which is a natural salt and can be discharged in the sea. The system comprises of a scrubber unit, usually placed in or around the funnel, a washwater treatment plant, a residue handling facility and an emissions monitoring system as imposed by the IMO for the continuous monitoring of sulfur emissions and other substances. The efficiency of the scrubber, and consequently the amount of $\mathrm{SO}_{\mathrm{x}}$ removed from the flue gas, can be adjusted according to the fuel used and the limitations of the region the ship is sailing. The final percentage of $\mathrm{SO}_{\mathrm{x}}$ emitted depends on the type of scrubber and the alkalinity of the water used. Apparently, the higher the amount of $\mathrm{SO}_{\mathrm{x}}$ removed, the higher the energy consumption of the scrubber.

The installation of a scrubber system is accompanied by the necessary pumps, coolers and tanks and in total it takes up a lot of space on the ship. This space is reserved from cargo space, especially in retrofits where the general arrangement does not facilitate the installation of such a system. The type and size of the scrubber affects highly the overall cost including installation and the lost cargo space.

\section{Enforcement of the regulations}

The responsible authority for ensuring compliance of the vessels in the high seas rests with the flag state. The flag state duties and jurisdiction over the vessels are mainly laid down under Article 94 of the United Nations Convention on the Law of the Sea (UNCLOS) (1982) and complemented by other articles. Only the flag state has jurisdiction over the registered ship regarding "administrative, technical and social matters" (United Nations, 1982), which includes the control of the ship's compliance with the regulations referred to marine pollution and ensuring that it is equipped with the necessary certificates that prove compliance. High seas are not strictly regulated and the lack of enforcement allows irresponsible flag states to avoid imposing heavy penalties to their ships, or in fact not imposing anything at all, to attract more ship owners with substandard ships (IMO, 2011). These flag states are called flags of convenience and attract ship owners that attempt to minimize the costs and sacrifice the quality or safety of their vessels.

On the other hand, the coastal state's jurisdiction is very restricted in case of vessels sailing in their waters without reaching a port. The coastal state has the right to inspect suspicious ships that have reached the port, but cannot stop a passing ship for inspection. If violations are detected, the port state control (PSC) can impose penalties to the operator or detain the ship in the port. The penalty policy of the coastal state very often requires assessment by the police and a court decision about a possible fine. A delegation of duties to the PSC would facilitate the procedure and minimize potential delays and waste of resources. PSC has gained experience in enforcement the past few years in the ECA zones, whereas flag states lack both the equipment and expertise in that field. An exception to this is the flag states that are also port states. A question whether the PSC is more fit to inspect and monitor the emissions is raised and an option to delegate PSC as the responsible authority for enforcement is discussed. 
MABR

4,2

\section{4}

\subsection{Port inspection}

Port inspection is a standard procedure followed by the PSC for ships at berth and the IMO approved methods for this inspection are the following:

- bunker delivery notes;

- ship's log books; and

- fuel samples.

The bunker delivery note is a legal document provided by the bunker supplier which indicates the type of fuel bunkered, the quantity, the quality, and its composition and properties. It has to be accompanied by a sealed fuel sample, signed by the supplier's representative. These documents do not consist a reliable method of inspection because they can be easily falsified as it has been proven in the past with cross checks with fuel samples. The responsibility lies on either the ship operator or the bunker supplier who provided a lower quality fuel that was not thoroughly checked by the master of the ship during bunkering.

One additional document checked in inspections is the ship's log book. The log book contains information about the fuel and oil handling procedures on board. The changeover from high to low sulfur fuel and the opposite, the volume of low sulfur fuels in each tank and the date, time, and position of the ship during the changeover, before entering or after exiting an ECA, are reported in the Oil Record Book. The log books sometimes do not provide useful information about the ship's compliance. Records are sometimes not in English, illegible because of handwriting or not recorded in good time, resulting in missing records or valuable information. Falsification of books is sometimes noticed when fuel samples are taken. Samples are either sent to a lab and results are obtained a few days later when the ship has left the port, or portable analyzers can be used to detect the sulfur level on the spot. Because of the reduced accuracy of these devices, the IMO has not approved them as legal evidence of noncompliance. If approved, they could accelerate the procedure of imposing a penalty, as it will become an administrative task, rather than a court order.

The above mentioned methods can be used for ships at berth and they have been proven accurate and reliable. However, they are very time consuming, need a lot of resources and can only be applied to ships in the port and not passing ships. Only a 10 per cent of the ships entering a SECA zone have been inspected using these procedures (CompMon, 2016). Inevitably, these methods cannot be used in the high seas.

It should be noted here that with the recent decision of the IMO to apply a "carriage ban" (of which more is given in Section 4.5), a ship that has no scrubbers will not be allowed to carry non-compliant fuels unless they are cargo; therefore, there can be no changeover of $\mathrm{HFO}$ to MGO or MDO, and the only possible changeover when entering an $\mathrm{ECA}$ will be from 0.5 per cent to 0.1 per cent fuel. However, this does not prevent operators who deliberately want to cheat to have a secret tank and/or a "magic pipe", which is used to divert oil to the combustion engine or discharge oil in the sea without using the oil separator, and allows the usage of $\mathrm{HFO}$ in the high seas.

\subsection{Airborne monitoring}

Several innovative systems have been developed lately to monitor the emissions from ships away from the coast. sulfur emissions have been already successfully measured for ships within a certain distance from the coast by approaching the ship's plume. Helicopters, unmanned aerial vehicles (UAVs) and special airplanes are able to measure the levels of pollutants directly from the ship's plume without interfering to the ship's course and 
activities. Airborne monitoring has the advantage of multiple inspections per flight, depending on the autonomy of the system used. The crew does not interfere with the measurements and consequently the results cannot be tampered with. This method has been successfully used by PSC in Denmark, Belgium and The Netherlands to target noncompliant ships. Because of lack of the IMO's approval for the method, port inspection is still required once the ship reaches a port. If inspection results are legally accepted as proof of guilt, fines will be issued on the spot without the need for a trial and port inspections could be minimized.

Helicopters, UAVs and airplanes with different range and flight duration can be deployed for airborne monitoring. The price of a cheap rotary drone can vary from USD1,523 to USD7,616 approximately. The maximum flight time of a rotary is $2 \mathrm{~h}$, depending on the payload, and covers an area of up to $5 \mathrm{~km}$. Professional drones, that can address more demanding tasks cost about USD1.7m with a maximum flight time of up to 6 $\mathrm{h}$, depending on the payload. Manned vehicles such as helicopters and airplanes have a wider range and flight duration compared to the unmanned vehicles. Their range can reach $200 \mathrm{~km}$ away from the coast and autonomy of a few hours. Unmanned vehicles have a more limited range, not only because of their specifications but also because of regulations that state that operators should have visual contact with them during the flight. Therefore, their range is limited to almost $25 \mathrm{~km}$ from the coast.

Unmanned vehicles are equipped with sensors, the most popular of which are the so called "sniffers". Before a measurement, targeting of suspicious ships takes place according to previous history of noncompliance, deviations from the expected route to avoid fixed stations of monitoring or even the color of the plume that could reveal the quality of the fuel if the helicopter is close enough to distinguish it. After targeting, a helicopter or UAV flies over the plume in a distance of approximately 30 to $50 \mathrm{~m}$ for a few seconds to obtain a measurement. They are usually equipped with a sniffer box containing electrochemical sensors for the detection of $\mathrm{SO}_{2}, \mathrm{NO}_{2}$ and $\mathrm{NO}$ and infrared sensors for $\mathrm{CO}_{2}$. The ambient air is pumped towards the sensors through the small tubes attached on the sniffer box and the $\mathrm{SO}_{2}, \mathrm{NO}_{2}$ and $\mathrm{CO}_{2}$ levels can be measured with an error of 0.01 per cent to 0.03 per cent. The autonomy of the UAV is limited and it depends on the payload. Therefore, the sniffer box is light-weighted and hard drives are not used, but data is directly stored in the cloud using a satellite connection.

For measurements further away from the coast, optical systems are used in combination with airplanes, as they can operate in higher speeds and bigger distances from the ship. Currently, they are able to detect $\mathrm{NO}_{2}$ and $\mathrm{SO}_{2}$ but the detection of $\mathrm{CO}_{2}$ is harder to implement and still under development. These systems do not reach the accuracy of the sniffers and they are only used as an indication of a gross noncompliance.

The advantages of accuracy and difficulty to tamper with the airborne systems make them a perfect choice for inspecting the emissions in the high seas. However, they have a limited range, are highly dependent on the weather conditions and have a considerable overall cost. The new specifications of UAVs might allow longer, more reliable flights in the ocean. Two types of UAVs are available in the market: the rotary drones and the fixed wing drones.

Fixed wing drones have longer flight time, much greater power capacity and payload. They can operate with sniffers or optical systems depending on the target but improvements are yet to be done before they are deployed in the high seas. A typical drone of this class can fly approximately $20 \mathrm{~h}$ without payload, which is satisfying, but any payload will substantially reduce the flight time. The maximum payload is $10 \mathrm{~kg}$ including the fuel and it can reach a cruise speed of $70 \mathrm{~km} / \mathrm{h}$. A payload of $5 \mathrm{~kg}$ is enough to reduce the 
MABR

4,2

206 flight time in half. The added payload reduces the fuel loaded on the UAV and therefore the flight time. The cost of such a drone can range from USD1.7m to USD3.41m including the necessary equipment. On the contrary, a rotary drone used for inspection in the ECA zones cost around USD150,000, considerably less than a fixed wing drone. In addition, it is still doubtful if the fixed wing drones can be immediately used in the high seas, as many improvements should be done to cope with the difficult conditions of the ocean, but their rapid development gives hope for use in 2020.

\subsection{Fixed stations monitoring}

Fixed station monitoring is relying on the very high quality of sensors adapted in key locations of the harbors around the world. They are analyzing the composition of the plume by using UV- fluorescence systems. In these systems, $\mathrm{SO}_{2}$ molecules' excitation by the UV light is used, and the fluorescence, which is a function of the $\mathrm{SO}_{2}$ concentration, is measured. The ambient air and pollution can mislead the measurement, the wind direction can divert the plume away from the sensor and give wrong or inadequate data and the number of ships in the surrounding area can confuse and give wrong results. Consequently, the required high quality of the sensors and the resulting high cost, does not necessarily guarantee an accurate measurement.

In Table I, an example of the costs per method is presented, as applied in Denmark. Costs were given in DKK but converted to USD.

Fixed stations with some important adjustments to withstand the extreme weather conditions, could potentially be used in the middle of the ocean. A floating measurement station installed in the main shipping routes could detect the sulfur emissions of the passing ships. Floating stations need not be fixed in a position, but with a satellite connection, their location can always be determined. If developed, a few considerations need to be taken into account. The sensors that will be used should be durable in extreme weather conditions and possible to maintain on the spot. If the stations are spotted by the ships, there is a possibility they will adjust their route to avoid them as they only have a limited range. For example, an optical measurement system has a maximum range of $5 \mathrm{~km}$.

\subsection{In situ emissions monitoring}

In situ emissions monitoring refers to measurements taken directly from the plume of the ship and reporting the information in real-time to the authorities. Hence, an overview of every vessel sailing in the high seas or restricted waters can be obtained at any time. An example of such an application is the regulation imposed for ships using scrubbers to de sulfurize their emissions and are legally bound to store relevant data on board for possible subsequent inspections. A similar device that measures the sulfur oxides from the stack of the ship can be designed to control the emissions in the high seas. However, a number of restrictions have delayed the development of such a device.

The main restriction opposed to its development is the sensitivity of the sensors that are used for that purpose. $\mathrm{SO}_{\mathrm{x}}, \mathrm{CO}_{2}$ and $\mathrm{NO}_{\mathrm{x}}$ sensors are sensitive to high temperatures and

\begin{tabular}{lcc}
\hline Surveillance method & Cost per year (USD) & Cost per inspection/ measurement (USD) \\
\hline Port inspection & 30,400 & 55 \\
Fuel samples & - & 91 \\
Airborne & 760,117 & 380 \\
Sniffer in Great Belt Bridge & 197,627 & 20 \\
\hline
\end{tabular}


could be destroyed if applied directly in the stack where the temperatures can be about $400^{\circ} \mathrm{C}$. A protective cover for the increased temperatures needs to be invented, and a secure connection to the shore for the transmission of data applied. Even though mandatory scrubber sensors are certified tamper-free, perhaps the safest way to ensure that it will not be possible to tamper with the data is to save the collected data in the cloud by transmitting in real time to shore with a satellite connection. Data are saved in a compressed format where it is impossible to track and edit the content. This compressed output can be transmitted to shore in real time using cloud solutions and satellite connection and can be

Sulfur cap in maritime transport analyzed quickly to spot any anomalies. The size of the emissions data is small enough to allow transmission without increasing considerably the cost for connection.

An important hindrance to this potential scheme is the party responsible for the initial investment. A device applied in the ship's stack would be at the cost of a ship owner who has no motive to proceed to such action. A regulation imposed by the IMO that obliges all ship owners to use these devices would be the only solution but it will find all ship owners against it since the overall cost of the new regulation is already burdening enough the shipping industry. The authorities will have to create incentives for the ship operators to install the device at their own cost which renders this scenario highly unlikely to happen in the limited time frame before 2020.

\subsection{Carriage ban}

In October 2018, MEPC 73 of the IMO adopted the carriage ban as a measure to tackle the possible noncompliance in the high seas in 2020. The measure will be implemented by 1 March 2020, as this is the earliest date possible for implementation because of the processes that need to be followed after the adoption. The carriage ban prohibits the carriage and loading of non-compliant fuel on ships that are not equipped with abatement systems and do not carry such fuel as cargo. In that way, the IMO aims to discourage ship owners to ignore the regulation and bunker HFO instead of low sulfur compliant fuel. Of course, it is still plausible for those who deliberately want to circumvent this rule to devise a method (such as a secret tank, or other) so that HFO is illegally used in the high seas, in the hope that this is not detected.

\section{Case studies}

Using predictions for the fuel prices in 2020, a method to calculate the profit of the noncompliant ships when burning high sulfur HFO instead of sulfur LSFO in the high seas is developed and used in case studies to present the approximate costs that this regulation introduces. In these case studies we assume that because of stricter enforcement the ship will not try to violate the sulfur regulations within an ECA, and that if a violation is registered it will only be outside the ECA. The main objective is to provide a tool that can be used to decide penalties reflecting the gravity of the violation rather than using uniform penalties that do not actually impose any financial loss to the non-compliant ship operators.

\subsection{The marine fuel market}

The supply and demand rules can help predict, up to a certain degree, the prices of marine fuels in 2020. The projections have a considerable margin error for the next two years because of political decisions and socio-economic changes that affect the demand and supply. For predicting the fuel prices in 2020, it is necessary to consider the uptake of scrubbers and LNG fueled ships as compliance method. According to the before mentioned study by CE Delft, three scenarios were used for the estimation. These are presented in Table II (CE Delft, 2016), as similar cases will be used in the case studies. Changes in 
MABR

4,2

208

transport demand, fleet composition and operational efficiency will lead in an overall increase of 8 per cent in the demand of marine fuels between 2012 and 2020. The uptake of scrubbers and LNG is expected to lead in a decrease for HFO from 228 million tonnes per year in 2012 to 36 million tonnes in 2020 in the base case and the new low sulfur fuel with a content of up to 0.5 per cent is expected to reach a demand of 233 million tonnes in the base case. MGO, MDO and Ultra LSFO (ULSFO), which is a maximum 0.1 per cent sulfur variant of LSFO, are expected to drop down to 39 million tonnes per year in 2020, while the demand only for MGO in 2012 was 64 million tonnes. The study by EnSys/Navigistics considered these calculations conservative and estimated a total demand of 342 million tonnes of marine fuels for 2020. Out of these, 195 million tonnes are expected to be marine distillates of 0.5 per cent sulfur or less and 48 million tonnes HFO. The demand for HFO is expected to drop about 44 per cent, from 253 to 48 million tonnes per year in the base case, which is 12 million tonnes more than the prediction of the study by CE Delft. Although the estimations in the studies are different, the conclusion is a drop for the demand of HFO and an increase of marine distillates.

In Figure 1, we can get a view of the behavior of fuel prices for 2016-2018 to help predict the prices in 2020.

Because of the unknown capacity of the refining industry in 2020, the variation of the estimations of the fuel prices is quite wide. The first estimations (IBIA, 2017), (Mattheou, 2018), (Grimmer, 2018), place the HFO price at an average of USD340 for the beginning of 2020 and a price differential with LSFO of approximately USD250. The price of HFO is expected to drop because of the reduced demand and the sudden demand of LSFO will cause a peak in its price the first semester of 2020, but is expected to drop gradually as demand and supply will reach an equilibrium.

\subsection{Methodology}

As mentioned, three scenarios will be used in the case studies. The low case scenario reflects a situation where the fuel prices are barely affected by the global sulfur cap. In the base case scenario, the market will respond to the new regulation within the expected limits and according to historical data. The high case scenario reflects a situation where the HFO price will plummet because of the very low demand and MGO will have a corresponding increase. Only a rough estimation of the price of the LSFO can be provided, as it is not yet available in the market. The assumed prices in the case studies are presented in the Table III. The fuel consumption of the ship in various engine loads is necessary for the evaluation of the volume of fuel consumed and the cost of fuel. Real fuel consumption was not possible to be obtained for every vessel examined; therefore, nominal fuel consumption for all engine loads is used. Engine loads and the corresponding nominal fuel consumption can be obtained from the data provided by engine manufacturers. Real fuel consumption has to be provided by the

\begin{tabular}{lccc}
\hline Sulfur content $(\% \mathrm{~m} / \mathrm{m})$ & $<0.10 \%$ & $0.10 \%-0.50 \%$ & $>0.50 \%$ \\
\hline Million tonnes per year & & & 38 \\
Low case & 33 & 198 & 36 \\
Base case & 39 & 233 & 14 \\
High case & 48 & 290 &
\end{tabular}

Table II.

Source: Assessment of fuel oil availability 2016 by CE Delft (2016) 


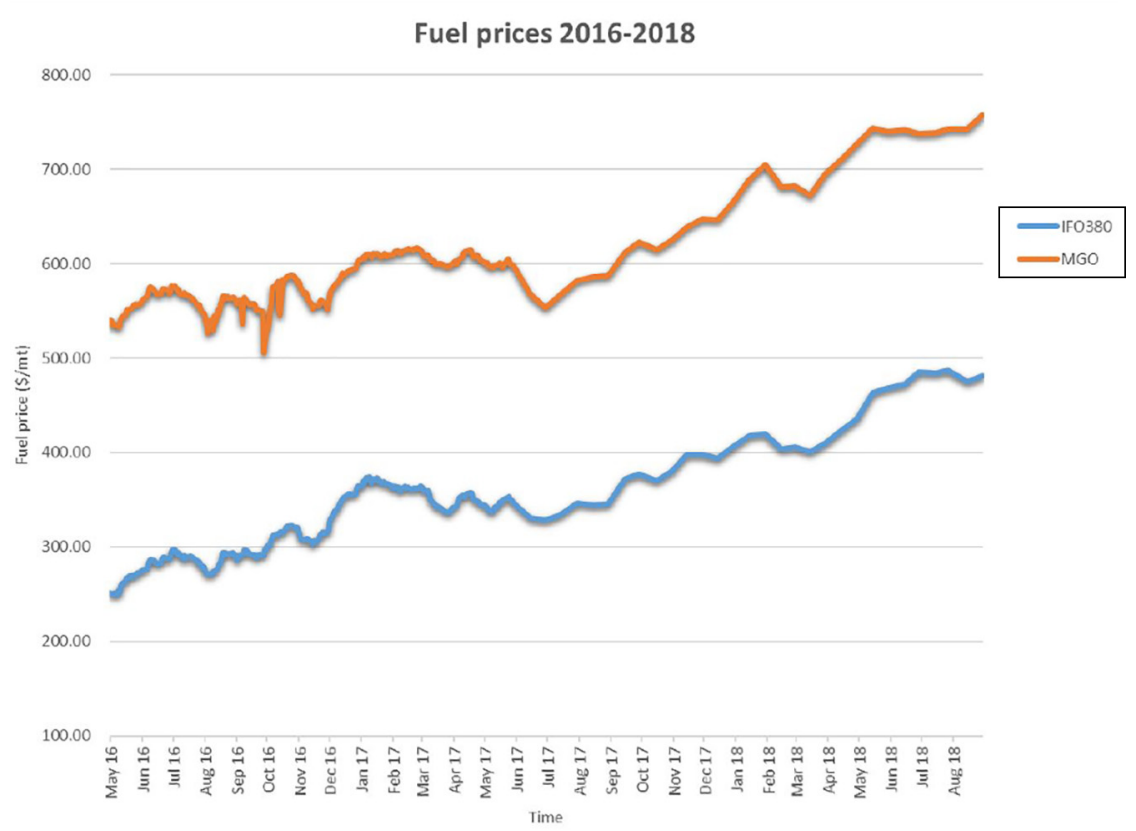

Source: Processed data from Bunkerworld

\begin{tabular}{|c|c|c|c|c|}
\hline & Low case & Base case & High case & $\begin{array}{l}\text { Table III. } \\
\text { Projected fuel prices }\end{array}$ \\
\hline $\mathrm{HFO}$ & 390 & 340 & 300 & for 2020 used in case \\
\hline MGO & 740 & 790 & 840 & studies (USD per \\
\hline $\mathrm{LSFO}<0.5 \%$ & 540 & 590 & 640 & tonne) \\
\hline
\end{tabular}

shipping company owning the vessel but this data is often treated as confidential. Therefore, we used the propeller law (or cubic law) instead (Zis et al., 2016). The engine load is dependent on the engine speed, the weather conditions and the loading condition of the ship. Using the sailing speed, we can estimate the engine load with equation (1):

$$
E L_{1} / E L_{2}=\left(V_{1} / V_{2}\right)^{n}
$$

According to Zis et al. (2016), values from $n=3.2$ or $n=3.5$ can be used for medium-sized vessels, tankers and feeder container ships, and higher exponents up to $n=4.5$ for fast container ships and in extreme weather conditions. In these case studies, cargo load and weather conditions are not taken into account as a general model for average situations is developed. The propeller law is applied with data about the average speed of the vessel from port to port. A drawback of the cubic law is the result returned in very low speeds (Psaraftis and Kontovas, 2013). It cannot be applied in very low or zero speed because it returns zero
Sulfur cap in maritime transport

Figure 1. Fuel prices May 2016-

Aug 2018. 
MABR

4,2

210

consumption, ignoring the fuel burnt while at berth. It would be preferable not to use a very low engine load and obtain more realistic results about the fuel consumption. In addition, considering manufacturer's recommendations for avoiding damage because of wear in the engine in low engine loads (MAN Diesel and Turbo, 2011), a lowest limit of 10 per cent will be used.

Specific fuel oil consumption (SFOC) values are obtained by the engine manufacturer's websites and the SFOC curves and tables they provide for every type of engine.

Fuel consumption of every vessel can then be estimated in equation (2):

$$
F C_{i}=10^{-3} * S F O C_{i} * E L_{i} * E P * t_{i}
$$

where $i$ is a specific engine loading condition, $\mathrm{FC}$ is the fuel consumption in tonnes, SFOC is given in $\mathrm{g} / \mathrm{kWh}, \mathrm{EL}_{\mathrm{i}}$ is the engine load in loading condition $\mathrm{i}, \mathrm{EP}$ expresses the installed engine power and $t_{i}$ is the sailing time for loading condition $i$ (Zis et al., 2016).

Speed is adjusted according to the engine load by using a minimum value at the minimum engine load and a maximum value at 100 per cent of engine load. The speed inside and outside ECA is optimized with the objective of minimizing the cost of fuel, given that fuel with 0.1 per cent sulfur is more expensive than 0.5 per cent. Consequently, we expect to have higher speeds outside ECA zones and lower speeds in ECAs.

For the specific case of containerships, the schedule imposed by the shipping company is a limiting factor to the speed of the vessel. These schedules are public and can be obtained by the operators' websites. Containerships were used for these case studies because of the ease of access to data that allow obtaining more accurate calculations. However, the model developed can be applied to any ship not equipped with a compliance method as LNG or scrubber. The model is not dependent on the type of ship but rather on the fuel consumption that depends primarily on the engine type. Distances between ports and distances traveled within ECA zones are acquired by MarineTraffic.

Engine specifications in combination with the vessel's schedule and speed are used to calculate the cost of fuel per trip in equation (3) and per nautical mile. The cost is calculated separately for both ECA and non-ECA zones assuming that compliant fuel are used in every case, i.e. 0.1 per cent sulfur inside and 0.5 per cent outside ECA zones. The total fuel cost results from the sum of the two independent costs, as shown in equation (4). For noncompliance, the fuel used is assumed to be HFO of 2.7 per cent sulfur:

$$
\begin{gathered}
\operatorname{Cost}_{k}=F C_{i, k} * F P_{j, k} \\
\operatorname{Cost}_{T O T A L}=\operatorname{Cost}_{E C A}+\operatorname{Cost}_{N O N-E C A}
\end{gathered}
$$

where $\mathrm{FP}_{\mathrm{j}}$ is the fuel price for the case scenario $\mathrm{j}$, and $\mathrm{k}$ characterizes the ECA or non-ECA sailing cost.

The main purpose of this task is the calculation of a minimum amount of fine that should be imposed if a ship gets caught for non-complying, as the fine should be dependent on the profits. A fine that highly exceeds the profits of the ship owner will be a deterrent factor for noncompliance in the future. Therefore, uniformity in the fines for the sulfur cap could lead to high noncompliance rates.

In the following, we examine two case studies to illustrate the method. Both case studies are in the container sector. This causes no loss of generality, as the methodology for other shipping sectors is the same. Both cases are based on realistic data, taken from container 
carriers' web sites, engine manufacturers' data and others. Names of ships or shipping companies are not disclosed and there is no implication, direct or indirect, of any intent not to abide by the sulfur regulations. In either case, the calculations are made solely to indicate the magnitude of the potential savings in fuel costs and hence guide relevant authorities on what kinds of fines can be imposed in the event deliberate noncompliance is manifested.

\subsection{Case study 1}

A large container ship $(18,000+$ TEU, $59,000+\mathrm{kW}$ maximum continuous rating [MCR]) is examined in the first case study. Assume the ship is deployed on a route from Asia to Europe and back, with a total of 10 port calls each way, of which 3 are inside the European ECA. At a speed corresponding to 80 per cent of MCR, the whole trip lasts approximately 84 days, of which almost 9 days are spent within European ECAs. The calculated fuel consumption per trip is presented in Table IV.

The SFOC values were retrieved by the engine manufacturer data published online. Using the engine load and SFOC values with the time spent inside and outside ECA, the fuel consumption and fuel cost for the three case scenarios were calculated. The fuel cost per trip and per nautical mile was calculated and the savings per trip and per nautical mile are presented in Table V. We clarify that savings per nautical mile are computed per nautical mile sailed in the high seas (outside ECAs), as this is where potential savings because of inappropriate use of HFO can be realized. The ship spends about 10 per cent of its time inside ECA zones and therefore the fuel cost for the sailing time inside an ECA is not as high as the one in the high seas. The difference in the total cost before and after 2020 is considerably high as the bunker consumption in the high seas is the prevailing value compared to the ECA consumption. To be compliant, the fuel cost for such a ship in 2020 will be 40 per cent more in the high case.

It is clear from this example that a ship of this type will enjoy a great profit by burning non-compliant fuel in the high seas. However, a fine equal to this profit might still be low; the ship owner would rather pay the fine and continue violating the rule. To be a credible deterrent, a multiple of the profit would serve as a better fine. This is of course a policy decision of the enforcement authorities.

\subsection{Case study 2}

The second container ship is smaller (4,650 TEU, 45,700+ $\mathrm{kW}$ MCR). The vessel is deployed on a route from Europe to the USA with 8-port calls roundtrip. Assuming again sailing at a

Table IV. Fuel consumption per trip

\begin{tabular}{lcccrr}
\hline & Cost HFO per trip & Cost LSFO per trip & Savings per trip & Savings per n.m. & Fuel costs and \\
\hline Low case & $1,848.26$ & $3,081.79$ & $1,233.52$ & 0.052 & savings for HFO and \\
Base case & $2,078.96$ & $3,419.75$ & $1,340.79$ & 0.057 & LSFO per trip (in \\
High case & $2,309.66$ & $3,757.71$ & $1,448.05$ & 0.061 & thousand USD) \\
\hline
\end{tabular}


MABR

4,2

212

speed corresponding to 80 per cent of MCR, total duration is 35 days. All of the port calls are within the Baltic and North Sea ECA and the North American ECA. As a result, the ship spends almost 50 per cent of its time inside ECA zones.

The cost of fuel during its trip is calculated using data from the engine manufacturer and is presented in Table VI.

The engine load and SFOC values are dependent on the speed of the vessel which was optimized for sailing inside and outside ECAs. The minimum SFOC is provided by the manufacturer as $171 \mathrm{~g} / \mathrm{kWh}$.

The fuel costs calculated for the three scenarios using the engine data are presented in Table VII. As before, savings per nautical mile are computed per nautical mile sailed in the high seas (outside ECAs), as this is where savings can be realized.

The size of the ship and the route followed play an important role in the amount of fuel cost per trip. As expected, the second container ship has lower fuel costs compared to the first one, because of not only the size of the ship which is considerably smaller but also the route followed. However, ship 2 spends 50 per cent of the sailing time inside ECA zones where the fuel consumed is considerably more expensive. Sailing with LSFO in spite of HFO will cost approximately 20 per cent more.

\section{Penalties}

Low fines and relaxed enforcement of the regulations will create a climate of noncompliance where it may be worth taking the risk of getting caught as the penalties will not reach the investment costs for scrubbers, LNG or even switch-over to LSFO. The highest fine for a non-compliant ship in Denmark, where government control is present and environmental regulations are strongly enforced, was USD60,000, by March, 2018 (VPO Global, 2018). However, this value is much lower than even the lowest savings among the two case studies examined (in the second case study a medium-sized container ship could save a minimum of about USD257,000 per trip). Therefore, it is recommended that the fines be higher, and specifically, exceed the profits of the trip to discourage similar behavior. Non-compliant ships should receive higher punishments and the frequency of inspections projected against the chance of a ship getting caught should be examined before deciding a fine, but because of lack of data, it was not possible to assess in this paper.

In Table VIII, fines imposed in European countries for violations inside ECA zones in 2015 are presented. All fines were converted to USD from each country's currency. It can be observed that there is not a common penalty policy, but it depends on the country and the

Table VI.

Fuel consumption per trip
Fuel consumption (tonnes)

ECA zones

919.24

High seas

$1,119.67$

Total

\section{Table VII.}

Fuel costs and savings for HFO and LSFO per trip (in thousand USD)

\begin{tabular}{lcccc}
\hline & Cost HFO per trip & Cost LSFO per trip & Savings per trip & Savings per n.m. \\
\hline Low case & $1,016.14$ & $1,273.66$ & 257.52 & 0.050 \\
Base case & $1,106.88$ & $1,386.80$ & 279.92 & 0.055 \\
High case & $1,197.63$ & $1,499.95$ & 302.31 & 0.059 \\
\hline
\end{tabular}


court decision in every case. This variety of the level of fines can create the impression that it is possible to get away with a violation paying a very low price.

An alternative but very effective penalty is detention in port. Currently, detention of a ship is possible when violations regarding the structural safety of the ship or the safety and health of the crew are found on board during the inspection of the PSC. Detention is a very costly penalty for ship owners, as a delay in schedule may result to loss of sensitive cargo that needs fast transportation. Failing to deliver the cargo on time could imply a fine to the operator because the terms of the contract were violated. In addition, the operative costs of the ship have to be covered immediately, despite the fact that it is not operating at the time, leading to considerable losses for the operator. An appeal for the fine imposed is not going to save any of the costs that the ship owner will be charged with. Detention has not been used so far for these violations, but it could be considered as a potential measure for special cases.

Other negative reinforcement methods could be the loss of insurance coverage if a ship is caught violating the regulation.

Fines are an inevitable measure but positive reinforcement can prove more effective in the long term.

Shipping companies will become more condescending and willing to carry the burden of the additional cost of the compliant fuel, if rewards to compliant ships are awarded by ports or port states. Advantages to law-abiding companies, lower port fees and taxes are some measures that can be used to call the shipping world to comply with the new regulation. The occasional controls by PSC can verify if ships comply. It is up to the port state and the port administration to decide whether such incentives will be applied or not, and what kind of incentives are possible to apply in every port.

\section{Conclusion}

The global sulfur cap imposing a new limit of 0.5 per cent sulfur content in the fuel consumed in the high seas has raised concern in the shipping world because of the high fuel costs that it implies but also the level of compliance in an area difficult to regulate and monitor like the high seas. The enforcement methods that can be used in the high seas are still under research as there are not any suggested methods by the IMO. All methods are analyzed, their advantages and limitations, as well as their feasibility and possible improvements. The enforcement schemes that are possible to use can be grouped in five categories:

(1) port inspection;

(2) airborne monitoring;

(3) fixed stations monitoring;
Sulfur cap in maritime transport

213

\begin{tabular}{lrr}
\hline Country & Maximum fine (USD) & \\
\hline Belgium & $6,823,240$ & \\
United Kingdom & $3,828,506$ & \\
United States & 25,000 per day & Table VIII. \\
Denmark & 57,424 & Fines in Europe, \\
Germany & 25,018 & Adapted from \\
Lithuania & 16,467 & International \\
Latvia & 3,298 & Transport Forum \\
Sweden & $1,111,233$ & Tran \\
Netherlands & $92,120+$ economic gains & (ITF, 2016) \\
\hline
\end{tabular}


MABR

4,2
(4) in situ emissions monitoring; and

(5) carriage ban.

Port inspection is conducted in the port and therefore ineffective in the case of enforcement in the high seas. The carriage ban is a measure in the right direction, but cannot address the full scale of the problem and will need to be implemented in parallel with other measures. On the other hand, airborne solutions are very promising but need further development. Investment in the development of in situ emissions monitoring solutions could prove very useful for the future as it will be the most effective and low cost solution, if the consequences of such a decision for the ship owners are anticipated.

The long procedure of definition of penalties could be standardized and accelerated with a model which calculates the profits of any ship, given the route and duration of the trip. This could help estimate the minimum amount of fine and there would be no need for the authorities to waste time and resources for court decisions about the violations. A model that calculates the profits for burning non-compliant fuel in the high seas was developed and was applied in two case studies. The calculations are based on the route followed, the amount and type of fuel burnt and the approximate fuel consumption. Inside the ECA zones, the vessels are considered to be compliant because of the strict enforcement and the speed of the vessels is optimized accordingly for the ECA areas. It was noticed that ships spending most of their time inside ECA zones have higher costs because of the higher price of the 0.1 per cent sulfur fuels, MGO and MDO. However, the profits in case of noncompliance are considerably smaller in this case of a reduced time sailing with HFO. The potential savings in the two case studies examined reached a maximum value of USD61 per (high seas) nautical mile, but even higher values are conceivable, depending on the scenario. It will be very profitable for ships sailing a long time in the high seas to risk noncompliance, given the level of the fines that have been imposed so far, unless a very strict enforcement takes place. In addition, this does not refer only to monitoring but also to the penalty system applied and its effectiveness.

A further study of the subject could lead to a calculation of fines that takes into account the probability of getting caught for noncompliance and the corresponding time a ship could be sailing in the high seas burning HFO.

Needless to say, a global harmonization of the system of fine calculation and imposition is considered of paramount importance for the overall effectiveness of enforcement of the global cap. The legal issues associated with this may be non-trivial but will need to be addressed all the same.

\section{Note}

1. Given the definition of LFSO, HFO in this paper is meant to be the standard, high-sulfur (typically 3.5 per cent) variant of fuel oil.

\section{References}

CE Delft (2016), "Assessment of fuel oil availability - final report”, Technical report, CE Delft, Stratas Advisors, UMAS, NMRI, Petromarket Research Group, and Shinichi Hanayama, July.

CompMon (2016), Compliance Monitoring Pilot for Marpol Annex vi, Events, Compmon Stakeholder Conference, 1 April.

Cullinane, K. and Bergqvist, R. (2014), "Emission control areas and their impact on Maritime transport", Transportation Research Part D, Vol. 28, pp. 1-5. 
Ensys Energy and Navigistics Consulting (2016), "Supplemental marine fuel availability study", Technical report, EnSys Energy, July.

Fagerholt, K. and Psaraftis, H. (2015), "On two speed optimization problems for ships that sail in and out of emission control areas", Transportation Research Part D, Vol. 39, pp. 59-64.

Fagerholt, K., Gausel, N., Rakke, J. and Psaraftis, H. (2015), "Maritime routing and speed optimization with emission control areas", Transportation Research Part C, Vol. 52, pp. 57-63.

Grimmer, R. (2018), "Expected pricing and economic impacts of the Imo 2020 rule", October, available at: https://stillwaterassociates.com/expected-pricing-and-economic-impacts-of-the-imo-2020-rule/

IBIA (2017), "How much will 2020 cost? The international bunker industry association (IBIA)", March, available at: http://ibia.net/how-much-will-2020-cost/

IMO (1978), International Convention for the Prevention of Pollution from Ships (MARPOL), Annex VI, International Maritime Organization (IMO).

IMO (2011), "Procedures for port state control". Resolution A.1052(27), International Maritime Organization (IMO).

ITF (2016), "Reducing sulphur emissions from ships: the impact of international regulation". Technical report, Organisation for Economic Co-operation and Development (OECD), International Transport Forum.

Jiang, L., Kronbak, J. and Christensen, L.P. (2014), "The costs and benefits of sulphur reduction mea-sures: sulphur scrubbers versus marine gas oil", Transportation Research Part D, Vol. 28, pp. 19-27, doi: 10.1016/j.trd.2013.12.005.

Lindstad, H. and Eskeland, G. (2016), "Policies leaning towards globalization of scrubbers deserve scrutiny", Transportation Research Part D, Vol. 47, pp. 67-76.

Lindstad, H.E., Rehn, C. and Eskeland, G.S. (2017), "Sulphur abatement globally in Maritime shipping", Transportation Research Part D, Vol. 39, pp. 303-313.

Lloyd's Register (2012), LNG-Fuelled Deep Sea Shipping, Lloyd's Register, August.

MAN Diesel and Turbo (2011), "Service Letter SL11-544/MTS”, Technical report, MAN B\&W, June.

Mattheou, D. (2018), “2020: Imo's sulfur cap - the next day what you need to know”, June, available at: www.naftemporiki.gr/afieromata/story/1355768/2020-imos-sulfur-cap-the-next-day-what-you-n

Molloy, N. (2016), “The IMO's 2020 global sulphur cap: what a 2020 sulfur-constrained world means for shipping lines, refineries and bunker suppliers", Technical report, S\&P Global Platts, October.

Panagakos, G., Stamatopoulou, I. and Psaraftis, H. (2014), "The possible designation of the mediterranean as a seca: a case study", Transportation Research Part D, Vol. 28, pp. 74-90.

Press Kristensen, K., Cristian, E. and Danish Ecocouncil, T. (2011), Cleaner shipping: focus on air pollution, technology and regulation, June.

Psaraftis, H.N. and Kontovas, C.A. (2013), "Speed models for energy-efficient Maritime transportation: a taxonomy and survey", Transportation Research Part C, Vol. 26, pp. 331-351.

Ship and Bunker News Team (2017), "Interest in LNG as a Marine fuel is growing following IMO sulfur cap decision, says supplier", Ship and Bunker, February, available at: https://shipandbunker.com/ news/apac/653365-interest-in-lng-as-a-marine-fuel - is-growing-following-imo-sulfur-cap-decisionsays-supplier

Svindland, M. (2018), "The environmental effects of emission control area regulations on short sea shipping in Northern Europe: the case of container feeder vessels", Transportation Research Part D, Vol. 61, pp. 423-430.

UNCLOS (1982), United Nations Convention on the Law of the Sea, United Nations.

United States Environmental Protection Agency (EPA) (2016), "Sulphur dioxide (SO2) pollution, United States Environmental Protection Agency (EPA)", August, available at: www.epa.gov/so2pollution/sulfur-dioxide-basicseffects 
MABR

4,2

216
VPO Global (2018), "Is non-compliance a financial incentive? Why the 2020 sulphur cap needs enforcement", March, available at: https://vpoglobal.com/2018/03/06/is-non-compliance-withthe-2020-sulphur-cap-a-financial-incentive

Zis, T. and Psaraftis, H. (2017), "The implications of the new sulphur limits on the European ro-ro sector", Transportation Research Part D, Vol. 52, pp. 185-201.

Zis, T. and Psaraftis, H. (2018), "Operational measures to mitigate and reverse the potential modal shifts due to environmental legislation”, Maritime Policy and Management, Vol. 52, pp. 1-16.

Zis, T., Angeloudis, P., Bell, M.G. and Psaraftis, H.N. (2016), "Payback period for emissions abatement alternatives: role of regulation and fuel prices", Transportation Research Record: Journal of the Transportation Research Board, Vol. 2549 No. 1, pp. 37-44.

\section{Corresponding author}

Harilaos N. Psaraftis can be contacted at: hnpsar@dtu.dk

For instructions on how to order reprints of this article, please visit our website: 